\title{
A Case Report with Literature Review: Recurrence of Peripheral Ameloblastoma with Intracranial Extension
}

\author{
Elneel Ahmed Mohamed Ali ${ }^{1}$, Shaza B M Mahjoub ${ }^{2 *}$, Mohamed Ezzaldin $^{3}$ and Mohamed Abdalhalim ${ }^{4}$ \\ ${ }^{1}$ University of Khartoum, Khatoum, Sudan
}

${ }^{2}$ Sudan medical specialization board, Khartoum, Sudan

${ }^{3}$ Sudan International University, Khartoum, Sudan

${ }^{4}$ International University of Africa, Khartoum, Sudan

Submission: December 01, 2020; Published: December 08, 2020

*Corresponding author: Shaza B M Mahjoub, Sudan medical specialization board, Khartoum, Sudan

Abstract

Introduction: Ameloblastoma is generally considered to be a benign lesion with locally invasive behavior and a tendency to reoccur after inadequate treatment. The risk of recurrence is reported to be significantly reduced by radical treatment compared with conservative surgical treatment.

Case Report: A 37 year's old male patient presented to Khartoum Dental Teaching hospital in July 2020 with painful firm pink fleshy mass with areas of necrosis in the parotid region that bleeds continuously and associated with sense of relief after bleeding, it started as small lesion that progressed in 10 months duration. The left eye underwent exophthalmos, hazy vision, severe pain and continuous tearing. The patient is operated two times in the last 15 years.

Conclusion: Peripheral Ameloblastoma can have an aggressive invasive behavior resembling malignancy. High rate intracranial extension can occur in short period making surgical intervention for complete removal of the lesion difficult and only confined to surgical debulking to improve quality of life. Close long term follows up of Ameloblastoma after primary treatment is mandatory.

Keywords: Ameloblastoma; Peripheral Ameloblastoma; Epithelial Odontogenic Tumours

Abbreviation: CT: Computed Tomography; Mequ/L: Milliequivalents Per Litre; MRI: Magnetic Resonance; Imaging; HB: Haemoglobin; KCL: Potassium Chloride

\section{Definition and Pathophysiology}

Ameloblastoma is the most common epithelial odontogenic tumour, and it accounts for $10 \%$ of all tumours that arise in the mandible and maxilla [1]. It is generally considered to be a benign lesion with locally invasive behaviour and a tendency to reoccur after inadequate treatment [2,3]. The risk of recurrence is reported to be significantly reduced by radical treatment compared with conservative surgical treatment. The tumour originates from the residual epithelium of tooth germ, epithelium of odontogenic cysts stratified squamous epithelium and epithelium of the enamel organ. About $80 \%$ of ameloblastoma occur in the mandible mainly the third molar region and the remaining $20 \%$ in the upper jaw [4], its peak incidence is in the third to fourth decades of life and male to female ratio is $1: 1[5,6]$. A slight male predilection and major occurrence in the mandibular ramus area were elicited. A study by Pagella et al. [7] showed that ameloblastoma express the neurotrophic factors as well as their receptors which are responsible for their innervation by trigeminal axons in vivo. In vitro studies using microfluidic devices showed that ameloblastoma cells attract and form connections with these nerves. Innervation of ameloblastoma might play a key role in the onset of this lesion and might represent a promising target for non-invasive pharmacological interventions.

\section{Case Report}

A 37 year's old male patient presented to Khartoum Dental Teaching Hospital in July 2020 with painful firm pink fleshy mass with areas of necrosis in the parotid region that bleeds continuously and associated with sense of relief after bleeding, 
it was started as a small lesion that progressed in 10 months duration. The left eye underwent exophthalmos, hazy vision, severe pain and continuous tearing. The patient was operated two times in the last 15 years the first operation in 2005, was segmental resection of the mandible and disarticulation in the same side of the presented lesion, the second operation in 2010, was excision of pleomorphic adenoma in the parotid gland and it was documented that the patient was anaemic. Computed Tomography (CT) scan of head and neck with contrast showed large heterogeneously enhancing lesion involved the left temporal lobe, left orbit, left nasopharyngeal space and left sphenoidal sinus with encasement of adjacent vessels. Two incisional biopsies were taken at two different occasions; The first from superficial area and showed a neoplasm composed of variably sized islands of odontogenic epithelium, reverse nuclear polarity and subnuclear vacuoles surrounded by fibrous connective tissue stroma, the centers of odontogenic epithelium had loose stellate reticulum cells, with foci of squamous differentiation; The features were consistent with ameloblastoma, The second biopsy was taken from more deep areas of the lesion measuring $2 * 1.5 \mathrm{~cm}$ showed tumour forming nests composed of two cell populations, central stellate cells surrounded by epithelial cells showed peripheral palisading with presence of inflamed fibrous connective tissue with no evidence of frank malignancy which is also consistent with ameloblastoma.

Investigations revealed low potassium (2.8Mequ/L) and Haemoglobin level of (HB 6.2) which indicated anaemia which can be explained by chronic blood loss from the lesion, and high total white blood cells the patient is admitted for correction of $\mathrm{HB}$ by giving 5 binds of whole blood preoperatively and correction of potassium by giving potassium chloride (KCL) $40 \mathrm{mmol}$ in $500 \mathrm{ml}$ normal saline. The patient was planned for surgical debulking and temporalis flap to cover the defect area. Under the most aseptic conditions the patient was operated under general anaesthesia to remove the Ff Figure exophytic mass, during procedure there was profuse bleeding and plenty of vessels ligated, which declared the presence of angiogenesis. A part of brain tissue is exposed after removal of the mass with cerebrospinal fluid leakage; unfortunately temporalis muscle of the affected side found to be destroyed by the tumour process, Small area of the temporal skin is rotated to cover the defect area. The excised mass (measuring $9 * 8 * 6 \mathrm{~cm}$ ) sent for histopathological assessment which showed tumour forming nests consisting of two cell populations, central stellate cells surrounded by epithelial cells showing peripheral palisading with presence of adjoining inflamed fibrous connective tissue and no evidence of frank malignancy which was consistent with ameloblastoma (Figures 1-3).

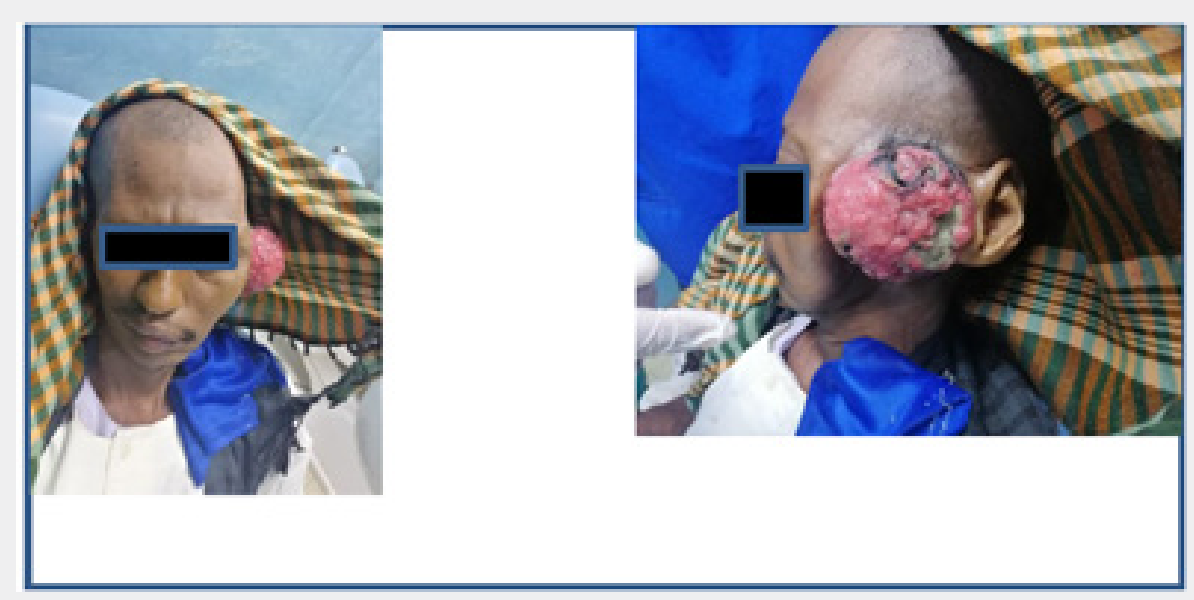

Figure1: Anterior and lateral aspects of the lesion.

\section{Literature Review and Discussion}

Intracranial and skull ameloblastomas are rare, with for example only 3 patients $(<1 \%)$ showed an intracranial manifestation in the large population of 315 ameloblastoma patients published by Olaitan et al. [8], Regarding the origin of temporal bone ameloblastoma, two hypotheses could be possible; The first theory of loco-regional primary growth and second theory of metastatic character of the secondary lesion, Regarding the loco-regional development hypothesis, a local recurrence could be possible despite histologically negative margins [9], by ameloblastic cells found in muscle tissue and resulting from dissemination during surgery $[10,11]$, which may be consistent with the fact that our patient operated before to remove ameloblastoma of the mandible that could be disseminated from. Bettoni et al. [12] reported A case of 26 years old patient from north Africa presented with recurrent mandibular ameloblastoma on routine follow-up CT scan imaging, an osteolytic temporal bone lesion, The extension was then further assessed by Magnetic Resonance Imaging (MRI) 


\section{Advances in Dentistry \& Oral Health}

and revealed an osteolytic soft tissue lesion with an extradural component resulted in a mass effect on the right cerebral parietal lobe, without any synchronous other lesion (lymphatic or pulmonary) which resembled the presentation of our case in that the temporal bone had been eaten away by the tumour.

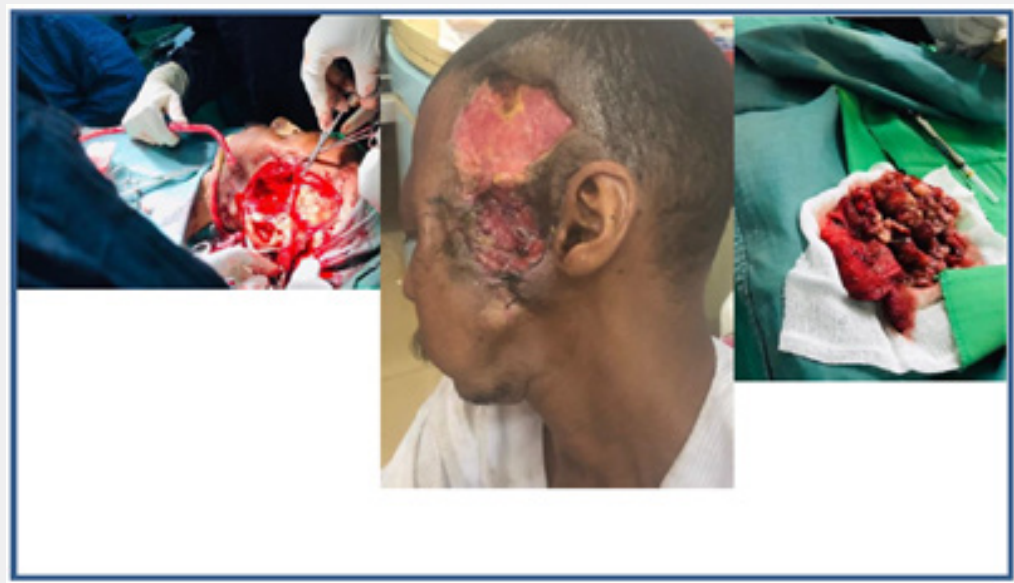

Figure 2: Intra-operative and post-operative views of the patient.

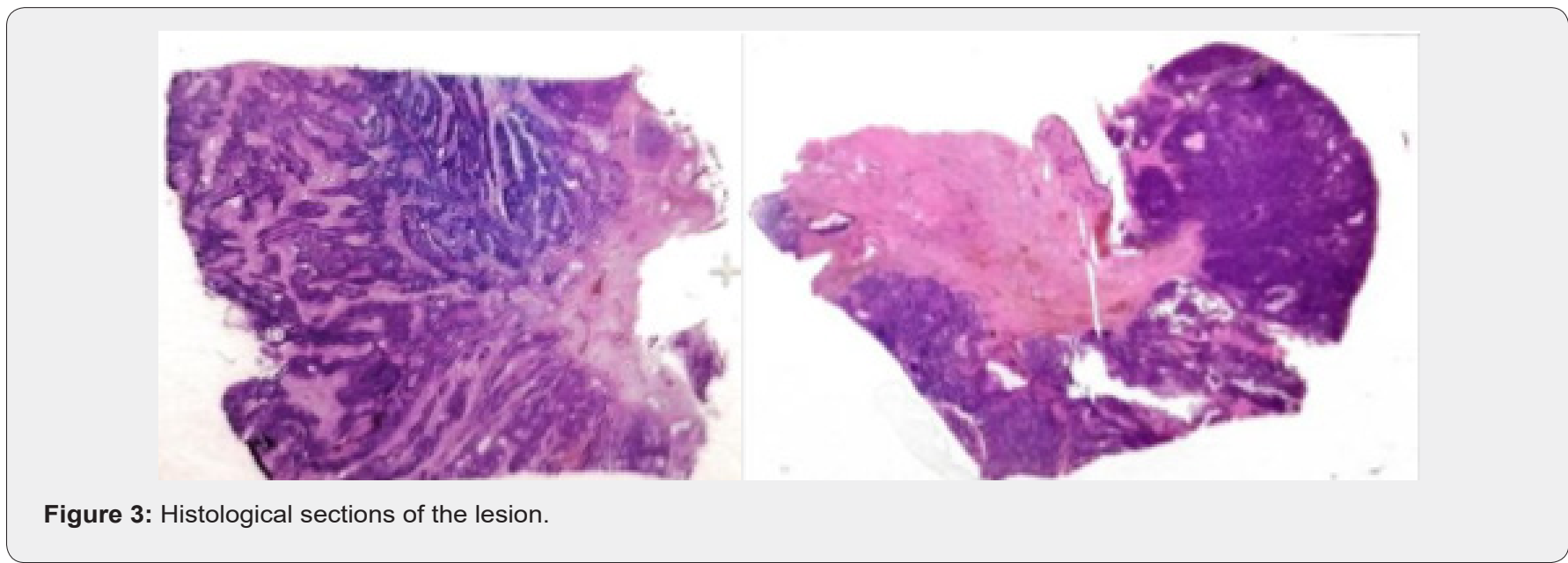

The invasion of the pterygo-maxillary fossa during the second recurrence suggested a dissemination of ameloblastoma cells along the fibres of the temporal muscles dating back to the resection of the coronoid process. Thus, invasion of the temporal bone by ameloblastoma is favoured over a true brain metastasis. Case of a 57-year-old patient who was admitted with a huge tumour involved the nasal cavity, the left maxilla, and the anterior fossa [13] which also presented with eye involvement consistent with our case. Tong et al. [14] presented a case of ameloblastoma reoccurred in the soft tissues after repeated curettage, This case illustrated that it is possible to treat ameloblastoma in accessible regions of the mandible by repeated curettage, thus sparing the patient morbidity of more ablative surgery for many years. The latest recurrence was unusual in that the recurrent lesion was located solely within soft tissue, which is also consistent with what we have of originally peripheral ameloblastoma invading bone. Olaitan et al. [15]; Arotiba et al. [16] described a recurrence rate to soft tissue of $19 \%$ and $13.3 \%$, respectively.

It was suggested that the recurrence of ameloblastoma may originate from the bone tissue left after tumour resection, from the invasion of adjacent tissue, or even after the dissemination of tumorous cells during the surgery. Muller \& Slootweg [17] stated that the majority of recurrences occur within 5 years of the primary treatment while we have a recuurence within 15 years from the first presentation. reported cases by Collings \& Harrison [18] of recurrent ameloblastoma after 49 years from the primary treatment. These studies reinforced the need for a long-term follow-up. Surgical procedures for initial and recurrent tumours are recommended. Surgical procedures for initial and recurrent tumours are recommended. Anastassov et al. [19] described the associated use of radiotherapy. According to Gardner [20], the 
use of radiotherapy should be restricted to inoperable lesions, whereas Pinsolle et al. [21] suggested a combination of surgery and radiotherapy for recurrent mandibular lesions which result from an inadequate primary surgery.

\section{Conclusion}

Peripheral Ameloblastoma can have an aggressive invasive behavior resembling malignancy. High rate intracranial extension can occur in short period making surgical intervention for complete removal of the lesion difficult and only confined to surgical debulking to improve quality of life. Close long term follows up of Ameloblastoma after primary treatment is mandatory.

\section{References}

1. Mendenhall M, Werning J, Fernandes R, Malyaba R, Mendenhall $\mathrm{N}$ (2007) Ameloblastoma. American journal of clinical oncology 30(6): 645-648.

2. Reichart P, Philipsen H, Sonner S (1995) Ameloblastoma: biological profile of 3677 cases. European Journal of Cancer Part B: Oral Oncology 31(2): 86-99.

3. Kim S, Jang H (2001) Ameloblastoma: A clinical, radiographic, and histopathologic analysis of 71 cases. Oral Surgery, Oral Medicine, Oral Pathology, Oral Radiology, and Endodontology 91(6): 649-653.

4. Masthan K, Anitha N, Krupaa J, Manikkam S (2015) Ameloblastoma. Journal of pharmacy \& bioallied sciences 7(Suppl 1): S167.

5. Larsson A, Almeran H (1978) Ameloblastoma of the Jaws: An Analysis of a Consecutive Series of all Cases Reported to the Swedish Cancer Registry during 1958- 1971. Acta Pathologica Microbiologica Scandinavica Section Pathology 86(16): 337-349.

6. Shear M, Singh S (1978) Age-standardized incidence rates of ameloblastoma and dentigerous cyst on the Witwatersrand, South Africa. Community dentistry and oral epidemiology 6(4): 195-199.

7. Pagella P, Caton J, Meisel C, Mitsiadis T (2020) Ameloblastomas Exhibit Stem Cell Potential, Possess Neurotrophic Properties, and Establish Connections with Trigeminal Neurons. Cells 9(3): 644.

8. Olaitan A, Adeola S, Adekeye E (1993) Ameloblastoma: Clinical features and management of 315 cases from Kaduna, Nigeria. Journal of CranioMaxillofacial Surgery 21(8): 351-355.

9. Luc J, (1988) Late loco-regional recurrences after radical resection for mandibular ameloblastoma. International journal of oral and maxillofacial surgery 17(5): 310-315.

10. Chen C, Miao Y (2002) Detachment and retraction of masticatory muscles from the jaw possibly transfers the residual tumor cells and causes extopic recurrence of ameloblastoma. Shanghai kou qiang yi xue= Shanghai journal of stomatology 11(1): 25-27.

11. Chen L, Li S, Yang H, Wang G, Zhang B (2006) Recurrent ameloblastoma of the anterior skull base: Three cases treated by radical resections. Journal of Cranio-Maxillofacial Surgery 34(7): 412-414.

12. Bettoni J, Neiva C, Fanous A, Olivetto M, Demarteleire C, et al. (2018) Brain ameloblastoma: metastasis or local extension case report and physipathological reflexion. Journal of stomatology, oral and maxillofacial surgery 119(5): 436-439.

13. Quick-Weller J, Koch F, Dinc N, Lescher S, Baumgarten P, et al. (2017) Intracranial ameloblastoma arising from the maxilla: an interdisciplinary surgical approach. Journal of Neurological Surgery Part A: Central European Neurosurgery 78(06): 582-587.

14. Tong AC, k BS, Yan W, Ip PP (2003) Recurrent ameloblastoma presenting as a soft tissue mass. Asian Journal of Oral and Maxillofacial Surgery 15(1): 5155.

15. Olaltan A. Arole G, Adekeye E (1998) Recurrent ameloblastoma of the jaws: a follow-up study. International journal of oral and maxillofacial surgery 27(6): 456-460.

16. Arotiba J, Ajike S, Akadir O, Fasola A, Akinmoladun V, et al. (2007) Odontogenic tumours: analysis of 546 cases from Nigeria. J Oral Maxillofac Surg 6: 44-50.

17. Müller H, Slootweg P (1985) The ameloblastoma, the controversial approach to therapy. Journal of maxillofacial surgery 13: 79-84.

18. Collings S, Harrison A (1993) Recurrent ameloblastoma? An historic case report and a review of the literature. British dental journal 174(6): 202-206.

19. Anastassov G, Rodriguez E, Adamo A, Friedman J (1998) Aggressive ameloblastoma treated with radiotherapy, surgical ablation and reconstruction. The Journal of the American Dental Association 129(1): 84-87.

20. Gardner D (1988) Radiotherapy in the treatment of ameloblastoma. International journal of oral and maxillofacial surgery 17(3): 201-205.

21. Pinsolle J, Michelet V, Coustal B, Siberchicot F, Michelet F (1995) Treatment of ameloblastoma of the jaws. Archives of OtolaryngologyHead \& Neck Surgery 121(9): 994-996.

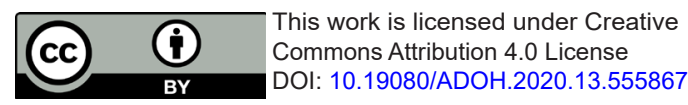

\begin{tabular}{l} 
Your next submission with Juniper Publishers \\
will reach you the below assets \\
- Quality Editorial service \\
- Swift Peer Review \\
- Reprints availability \\
- E-prints Service \\
- Manuscript Podcast for convenient understanding \\
- Global attainment for your research \\
- Manuscript accessibility in different formats \\
( Pdf, E-pub, Full Text, Audio) \\
- Unceasing customer service \\
Track the below URL for one-step submission \\
https://juniperpublishers.com/online-submission.php \\
\hline
\end{tabular}

